\title{
JUNTA DE COORDINACIÓN Y DIPUTADOS ÚNICOS: PROBLEMAS DE EXCLUSIÓN ${ }^{1}$
}

\author{
José Ramón Cossío DíAZ
}

\section{INTRODUCCIÓN}

La litis de la acción de inconstitucionalidad 4/2005 nos instaba a analizar la conformidad del artículo 34 de la Ley Orgánica y de Procedimientos del Congreso del Estado de Michoacán (en adelante LOPCM) con la Constitución federal. Según este precepto, solamente los coordinadores de grupo parlamentario pueden integrar la Junta de Coordinación Política del Congreso estatal. ${ }^{2}$ Esta regla contrasta con la que regía antes de que el citado artículo fuera reformado en enero de 2005. Según la regla ante-

1 Voto particular que suscribió el ministro José Ramón Cossío Díaz en la acción de inconstitucionalidad 4/2005, fallada por el Pleno de la Suprema Corte de Justicia de la Nación el 14 de enero de 2008. El autor agradece a Francisca Pou Giménez su colaboración en la elaboración del mismo. El ministro explica las razones por las que votó en contra de la resolución que declaró conforme con la Constitución la exclusión de los diputados únicos de partido de la Junta de Coordinación Política del Congreso de Michoacán. Su diálogo con la mayoría del Pleno muestra un debate interno entre diferentes perspectivas de ejercicio de la jurisdicción constitucional y diversas maneras de identificar los límites y las condiciones que la Constitución impone al Poder Legislativo, no ya respecto del contenido de las leyes sino de sus dinámicas internas de decisión.

2 El artículo 43 dispone lo siguiente: "La Junta de Coordinación Política es un órgano colegiado integrado por los coordinadores de los grupos parlamentarios, quienes ejercerán un voto ponderado; y por el presidente de la mesa directiva, quien sólo tiene derecho a voz. En caso de empate emitirá voto de calidad el presidente de la Junta". 
rior, la Junta estaba integrada por los coordinadores de grupo y por los diputados únicos de partido. ${ }^{3}$

El día de hoy hemos debatido la constitucionalidad del artículo a la luz de los cuatro argumentos formulados por los 14 diputados que interpusieron la acción. Con el respeto acostumbrado, expondré en este voto las razones por las cuales discrepo de la resolución adoptada por el Pleno. Aunque coincido con la mayoría de mis colegas en que no podía hablarse en el presente asunto de "leyes privativas" ni de negación retroactiva de derechos, no comparto con ellos la perspectiva desde la cual estos dos primeros argumentos han sido abordados ni el argumento básico por el que siete de ellos han declarado infundado el tercero de los cargos de inconstitucionalidad. ${ }^{4} \mathrm{La}$ determinación del Pleno respecto de este último punto ha sido que el artículo impugnado no contraviene los principios de equidad y representatividad políticas en la integración de los órganos parlamentarios porque el artículo 116 de la Constitución federal "nada dice" acerca de las normas que deben regir la estructuración orgánica de las cámaras estatales. Se trata, se ha apuntado, de una cuestión que el texto federal delega por completo al Constituyente y al legislador estatal.

A mi juicio, sin embargo, la tesis de la "delegación pura" en los términos en que ha sido manejada es Constitucionalmente inasumible y no guarda coherencia con lo que esta Corte ha sentado en algunos precedentes recientes, que han empezado a construir criterios para determinar qué es lo que la Constitución obliga a respetar en el ámbito de los procedimientos democráticos de decisión. La cuestión de fondo es difícil y todo argumento de constitucionalidad en este terreno debe ser extremadamen-

3 El texto vigente antes de la reforma era éste: "La Junta de Coordinación Política es un órgano colegiado integrado por los coordinadores de los grupos parlamentarios y por el o los diputados únicos de partido, quienes ejercerán un voto ponderado; forma también parte de la Junta el presidente de la mesa directiva, quien sólo tiene derecho a voz. En caso de empate, emitirá voto de calidad el presidente de la Junta".

4 No me detendré mayormente en el análisis del cuarto argumento, según el cual el artículo 34 de la LOPCM es inconstitucional porque contradice lo dispuesto en el artículo 35, que no fue impugnado y que establece las funciones básicas de la Junta. En la resolución este planteamiento se califica de inoperante porque — se asienta - la contradicción de un precepto legal con otro nunca puede originar un vicio de inconstitucionalidad, conclusión que no comparto pues a mi juicio la contradicción entre los contenidos de dos preceptos de rango legal muy bien puede revelar la incompatibilidad con la Constitución de alguno de ellos (o de los dos); no creo entonces que procediera negar por esta vía la relevancia o procedencia del análisis. 
te circunscrito y cuidadoso, pues se trata de evaluar las reglas de integración de la Junta a la luz de estándares jurídicos muy generales que remiten en última instancia al principio democrático y al respeto a la pluralidad política en la conformación de la voluntad parlamentaria.

Pero lo que no me parece dudoso es que el argumento usado por la mayoría está desencaminado. Del mismo modo que hemos abandonado la idea de que las violaciones al procedimiento legislativo son irrelevantes y quedan "convalidadas" por las votaciones finales, por ser ello incompatible con un sistema político que consideramos valioso porque los representantes populares deciden mediante la regla de la mayoría pero también porque antes de la votación hay una deliberación en la que las minorías tienen derecho a expresarse, no puede afirmarse que nuestra Constitución sea totalmente muda respecto de las reglas de funcionamiento de las cámaras legislativas estatales (ni cabe asumir a modo de presunción no rebatible, como hace la resolución, que la elección entre las diferentes opciones regulativas en ese ámbito en ningún caso pueden derivar en una violación a las muy generales previsiones de los artículos $40,41,115,116$ o 124 de la carta magna).

La Constitución no es compatible con cualquier tipo de conformación de ese órgano parlamentario. El hecho de que las autoridades estatales tengan competencia exclusiva para emitir la normativa respectiva no implica que le puedan dar el contenido que deseen; uno puede muy bien imaginar esquemas de organización de la Junta que no serían calificables de "democráticos" o de "representativos" bajo ninguno de los entendimientos posibles de estos conceptos. De ahí que decidir acerca de la constitucionalidad del artículo 34 de la LOPCM exigiese un delicado análisis sustantivo que la resolución, con el argumento de la delegación pura, omite desplegar.

\section{RECLAMOS INDIVIDUALES VS. CORRECCIÓN DE LAS ESTRUCTURAS}

Antes de desarrollar las tesis anteriores, deseo referirme brevemente a la cuestión de la naturaleza del asunto jurídico bajo examen. Lo primero que el debate nos ha llevado a discutir, al abordar los dos primeros argumentos formulados en la demanda, es la naturaleza de los reclamos que esta Corte está llamada a analizar en vía de acción de inconstitucionali- 
dad, en contraste con aquellos cuya vía natural de dilucidación es — por el contrario- el juicio de amparo.

La mayoría ha respaldado el día de hoy una posición — enraizada en el caso Temixco ${ }^{5}$ según la cual en una acción de inconstitucionalidad pueden examinarse todo tipo de violaciones a la Constitución federal. A esta posición hemos contrapuesto algunos ministros la idea de que existe una perspectiva de análisis que singulariza el juicio de constitucionalidad que la Corte debe desplegar en vía de acción. Debido a que la acción de inconstitucionalidad es un medio de control abstracto, no vinculado con un enfrentamiento de pretensiones específicas y en cuyo contexto es impropio hablar de poderes públicos con "interés jurídico" en la impugnación (en el sentido que esta expresión ha adquirido en el contexto del amparo), lo que el caso examinado nos obligaba a determinar no era la corrección o incorrección de excluir de la Junta de Coordinación Política al diputado $\mathrm{X}$ o $\mathrm{Y}$ a raíz de la reforma, sino la compatibilidad con la Constitución de unas determinadas normas de derecho parlamentario.

La acción de inconstitucionalidad, en otras palabras, no está diseñada para responder si se han violado los derechos fundamentales de las personas concretas que en un determinado momento ocupan los cargos a que la Constitución se refiere cuando define la legitimación para interponerla (el procurador general de la República, los diputados en una legislatura estatal, etcétera) sino para analizar la adecuación o inadecuación abstracta de ciertas normas con la Constitución. El grado de afectación de estas normas sobre la ciudadanía o sobre ciertos individuos puede ser una de las razones que permita decretar esa incompatibilidad abstracta, pero en cualquier caso los efectos de esa declaración no serán definidos en función de su impacto en la esfera concreta de derechos e intereses de ciertos individuos. De modo que, aunque es cierto que ningún precepto constitucional está formalmente excluido de la posibilidad de ser reivindicado en una acción de inconstitucionalidad, la perspectiva desde la cual deben extraerse en su contexto los contenidos normativos relevantes no es la perspectiva subjetiva y concreta que se adopta en el juicio de amparo y que permite desembocar en resoluciones restitutorias concretas.

5 Véase la controversia constitucional 31/97, interpuesta por el municipio de Temixco, y en particular la tesis jurisprudencial plenaria 98/99: Semanario Judicial de la Federación y su Gaceta, t. X, septiembre de 1999, p. 703. 
Por ello, a mi juicio los dos primeros argumentos, basados en la idea de normas privativas y de retroactividad desfavorable a ciertas personas, debían haber sido "leídos" en otra clave y su análisis debía haber sido claramente postergado para abordar en primer lugar la cuestión central: la compatibilidad o incompatibilidad de las nuevas normas sobre integración de la Junta con las reglas constitucionales sobre estructuración orgánica de los congresos estatales.

Las circunstancias que rodearon la reforma permitían argumentar en términos "subjetivos": según se desprende de los antecedentes, la reforma al artículo 43 fue realizada por la Legislatura saliente cuando ya se conocía la composición de la Legislatura derivada de las elecciones de noviembre de 2004 - por ello hablan de una reforma "con destinatario específico", de la violación al "principio de abstracción de la ley" y del desconocimiento de "derechos adquiridos"-. Pero como sostuve en la discusión de la controversia constitucional 9/2004, la Corte debía haber delimitado qué efectos de ciertas reformas orgánicas afectaban a las funciones de esos órganos y debían ser privilegiadas por el control vía controversia constitucional y cuáles únicamente a aspectos concretos y personales de las personas involucradas y debían ser objeto de análisis por la vía de amparo en el caso de que esas personas interpusieran el mismo. ${ }^{6}$

6 Cuando se resolvió la controversia 9/2004 argumenté que las resoluciones que ponen fin a las controversias declarando la inconstitucionalidad de algún precepto, al tener efectos generales, otorgan un "mayor beneficio" respecto de las que hacen lo propio desde el juicio de amparo. Sostuve también que las consideraciones de las sentencias en vía de controversia y acción de inconstitucionalidad tienen fuerza obligatoria para los jueces de distrito (entre otras instancias jurisdiccionales) en términos del artículo 43 de la Ley Reglamentaria de las Fracciones I y II del Artículo 105 de la Constitución federal. Por ello defendí que si en un caso se llegara a resolver una controversia antes que un juicio de amparo relativo al mismo planteamiento, las consideraciones emitidas por la Corte deberían considerarse vinculatorias del sentido del juicio de garantías, lo cual fortalecería la seguridad jurídica. En esta línea proponía que, cuando se promueven ambos medios de control constitucional contra de los mismos preceptos, sería muy conveniente que la Suprema Corte acordara y solicitara al órgano jurisdiccional correspondiente el aplazamiento de la resolución de los juicios de amparo relacionados con la controversia en tanto el alto tribunal se pronunciara sobre la constitucionalidad de la norma impugnada. Si la resolución de la Corte llegara a declarar la invalidez de la norma general impugnada ello no sólo beneficiaría a los promoventes del amparo sino que, por sus efectos generales, la sentencia beneficiaría a la totalidad de destinatarios de la norma, aumentado la efectividad del control de la regularidad constitucional del ordenamiento. 
La mayoría de mis colegas ha soslayado esta distinción en el primer bloque de consideraciones de la sentencia.

\section{LOS PROBLEMAS DE LA "DELEGACIÓN PURA" Y LA DEMOCRACIA DELIBERATIVA}

La Constitución federal no incluye normas detalladas que incidan en la regulación del funcionamiento de los congresos locales. Como se destacó en la acción de inconstitucionalidad 13/2000 — extensamente transcrita en las páginas 79 a 95 de la sentencia- lo único que el artículo 116 de la Constitución federal consigna en este punto es la necesidad de respetar el principio de división de poderes, el principio de elección directa de las legislaturas locales, la proporcionalidad representativa en relación con el número de habitantes y las reglas fundamentales en materia electoral (tanto para la elección de los disputados locales como para su relección). ${ }^{7}$

Sin embargo, y a diferencia de lo que asume la resolución, ni el precedente citado ni la escasez y abstracción de normas explícitas sobre este punto en la Constitución Federal permiten concluir que la integración y el funcionamiento de los órganos internos de un Congreso local son aspectos soberanamente determinables por la Constitución y las leyes estatales, sin que quepa en ningún caso afirmar que las normas relativas son

7 El artículo 116 de la Constitución incluye algunas otras disposiciones generales relativas a otros brazos del poder público; las mismas refieren los órganos que deben ejercer el Poder Judicial de los estados, la necesidad de garantizar su autonomía e independencia, la forma y términos en que deben designarse los funcionarios judiciales, las garantías mínimas que las Constituciones y leyes locales deben contener en materia electoral y la manera de celebrar convenios entre la Federación y los estados. El contenido de los artículos 40, 41, 115 y 124, también señalados en la demanda, es todavía más general. El 40 establece que el pueblo mexicano se constituye en una República representativa, democrática, federal, compuesta de estados libres y soberanos en su régimen interior pero unidos en una Federación según los principios constitucionales; el 41 dispone que el pueblo ejerce su soberanía mediante los poderes de la Unión en los casos de su competencia y por los estados en lo que toca a su régimen interior, en los términos de las Constituciones federal y estatales; y el 115, en la parte conducente, establece que los estados adoptarán para su régimen interior la forma de gobierno republicano, representativo, popular, teniendo como base su división territorial y organización el municipio libre; el 124, finalmente, dispone que las facultades no expresamente concedidas por la Constitución federal a los funcionarios federales se entienden reservadas a los estados. 
inconstitucionales. ${ }^{8}$ Como anunciaba arriba, aunque la libertad regulativa de los estados es amplia, puede darse perfectamente el caso de que las reglas de funcionamiento del Congreso estatal sean tales que ya no pueda seguir afirmándose que estamos ante un órgano que decide de modo democrático o, más específicamente, que se respeta el pluralismo político en la formación de la voluntad parlamentaria.

Pero ¿cómo construir un estándar de constitucionalidad adecuado para el caso? ¿Cómo emprender el trazado de límites tan sinuosos? ¿A partir de qué elementos fiscalizar al legislador delimitando las opciones inaceptables pero preservando su competencia para elegir libremente entre todas las constitucionalmente legítimas?

A mi juicio, la Corte debía abordar la construcción de esos elementos a modo de extensión de los principios y estándares fijados al resolver la acción de inconstitucionalidad 9/2005, interpuesta por el Partido Revolucionario Institucional contra una reforma a la Constitución del Estado de Aguascalientes. En esa ocasión, la Corte abandonó la tesis según la cual las violaciones al procedimiento legislativo quedan "convalidadas" una vez se producen las votaciones finales ${ }^{9}$ y esbozó un estándar para evaluar cuáles entre ellas originaban un vicio de inconstitucionalidad y cuáles, por el contrario, debían considerarse intrascendentes desde esa perspecti-

8 La tesis de la "delegación pura" se rastrea reiteradamente en la resolución en pasajes como los siguientes: "es claro que estas disposiciones constitucionales no se violentan con la reforma al precepto que venimos tratando, ya que de cualquier forma se mantiene la representación de la voluntad popular en el Pleno del Congreso de Michoacán de Ocampo, que es lo que protege la Constitución federal" (p. 79); “[c]omo puede advertirse claramente, el artículo 116 de la Constitución General de la República no establece norma alguna en relación a la forma como deben conducirse las legislaturas locales en la toma de decisiones, en su integración, designación de su personal o en el manejo de los recursos económicos que les son asignados, ya que esto sólo compete al Poder Reformador local y a los congresos de los estados, por tratarse de atribuciones que las entidades federativas se reservan al constituir el pacto federal" (p. 83, en trascripción proveniente de la acción 13/2000). Véanse también las páginas 87, 90 y 95 de la sentencia.

9 Véase por ejemplo la tesis P./J. 94/2001, de rubro "VIOLACIONES DE CARÁCTER FORMAL EN EL PROCESO LEGISLATIVO. SON IRRELEVANTES SI NO TRASCIENDEN DE MANERA FUNDAMENTAL A LA NORMA" (Semanario Judicial de la Federación y su Gaceta, t. XIV, agosto de 2001, p. 438) o la P./J. 117/2004, de rubro "PrOCESO LEGISLATIVO. LOS VICIOS DERIVADOS DEL TRABAJO DE LAS COMISIONES ENCARGADAS DEL DICTAMEN SON SUSCEPTIBLES DE PURGARSE POR EL CONGRESO RESPECTIVO" (Semanario Judicial de la Federación y su Gaceta, t. XX, diciembre de 2004, p. 1111). 
va. El citado asunto tiene claros puntos en común con el presente porque se centraba en el seguimiento de las etapas del proceso legislativo formal, mientras que el que hemos debatido hoy se refiere a una etapa previa pero igualmente vinculada a la formación de la voluntad parlamentaria, pues se relaciona con las reglas de integración y voto de un órgano - la Junta de Coordinación Política del Congreso estatal- que tiene un papel esencial en la conformación de la voluntad parlamentaria.

En la acción 9/2005 esta Corte contrapuso a una concepción puramente "mayoritarista" decimonónica de la democracia representativa - en la que el concepto de voluntad general se identifica simple y automáticamente con la voluntad nacional de la mayoría representada en la asamblea - una concepción deliberativa que la entiende como un sistema de gobierno

valioso no solamente porque en su contexto las decisiones se toman por una determinada mayoría de votos de los representantes de los ciudadanos, sino porque aquello que se somete a votación ha podido ser objeto de deliberación por parte tanto de las mayorías políticas como de las minorías políticas. Es precisamente el peso representativo y la naturaleza de la deliberación pública lo que otorga todo su sentido a la reglamentación del procedimiento legislativo - $\mathrm{y}$ a la necesidad de imponer su respeto incluso a los legisladores mismos cuando actúan como órgano de reforma constitucional-. ${ }^{10}$

Por ello, destacamos, "la adopción de decisiones por mayoría es una condición necesaria pero no suficiente para que pueda hablarse de democracia". ${ }^{11}$ Junto a la regla de la mayoría hay que tomar también en consideración el valor de representación política material y efectiva de los ciudadanos que tienen todos y cada uno de los grupos políticos con representación parlamentaria (así sean los más minoritarios) y el modo en que la aportación de información y puntos de vista por parte de todos contribuye a la calidad de aquello que finalmente se somete a votación. ${ }^{12}$ Si sólo se concede eficacia invalidatoria a las infracciones a las reglas de votación, subrayamos finalmente, las garantías institucionales de la deliberación plural desaparecen; dado que por su propia naturaleza las minorías están destinadas a no imponerse en la votación final a menos que su

10 Véase la página 75 de la sentencia.

11 Idem.

12 Véanse las páginas 75 y 76 de la sentencia. 
opinión coincida con un número suficiente de otras fuerzas políticas, el respeto a las reglas que garantizan la participación efectiva de las minorías en la etapa de negociación y debate resulta de crítica importancia. ${ }^{13}$

A la luz de estas premisas, concluimos, para determinar si en un caso particular se han respetado las condiciones básicas para el desarrollo de la deliberación democrática, la Corte debe supervisar el cumplimiento de tres puntos fundamentales:

1. El desarrollo del procedimiento legislativo debe respetar el derecho a la participación de todas las fuerzas políticas con representación parlamentaria. Por ello es necesario que se respeten los cauces que permiten tanto a las mayorías como a las minorías parlamentarias expresar y defender su opinión en un contexto de deliberación pública, lo cual otorga relevancia a las reglas de integración y quórum en el seno de las cámaras y a las que regulan el objeto y el desarrollo del debate.

2. El procedimiento deliberativo debe culminar con la correcta aplicación de las reglas de votación establecidas.

3. Tanto la deliberación parlamentaria como las votaciones deben ser públicas. $^{14}$

A las infracciones procedimentales sin impacto en la satisfacción de las anteriores condiciones, por el contrario, tanto por economía procesal como por la necesidad misma de no invalidar a la ligera las decisiones de los representantes ciudadanos, acordamos que no procedía otorgarles fuerza invalidatoria.

Cabe hacer dos señalamientos finales sobre el esquema de análisis anterior. El primero es que, como subrayamos en el precedente citado, al desplegar un juicio de constitucionalidad basado en estos estándares es importante conservar una perspectiva general que contemple el procedimiento legislativo en su integridad, puesto que de lo que se trata es precisamente de determinar si el desconocimiento de un fragmento particular de regulación parlamentaria impacta o no en la regularidad de la

13 Véase la página 76 de la sentencia.

14 En el contexto debatido en la acción 9/2005 este requisito se refería a la necesaria publicidad de la deliberación y de las votaciones finales, sin que ello implique que no haya etapas tempranas de formación de la voluntad parlamentaria en las que los debates pueden no ser públicos. 
decisión final. Los anteriores criterios, en otras palabras, no pueden proyectarse aisladamente sobre todas y cada una de las normas que tengan algo que ver con el funcionamiento parlamentario, pues su función es evaluar estructuralmente la normativa sobre toma de decisiones; cada norma debe ser interpretada sistemáticamente y de un modo atento a la función estructural de las mismas. Y el segundo es que cada resolución de la Corte en este ámbito debe servir para proveer una creciente concreción a las implicaciones de estos estándares, de modo que, con el tiempo, la jurisprudencia debe proveer un abanico internamente coherente de subestándares que vayan revelando la sustancia de los límites constitucionales a nuestros procesos de decisión democráticos.

\section{LOS PROBLEMAS DE EXCLUIR A LOS DIPUTADOS ÚNICOS DE PARTIDO}

A mi juicio, en el asunto que hoy nos ha ocupado la Corte debía continuar desarrollando y concretando las implicaciones de los estándares anteriores $\mathrm{y}$, desde esa perspectiva, creo que hay razones suficientes para dudar que el artículo 34 de la LOPCM supere el primero de ellos.

En mi opinión, la exclusión de los diputados únicos de partido de la Junta de Coordinación Política tiene un impacto desproporcionado sobre la posibilidad de que las fuerzas parlamentarias minoritarias puedan intervenir en la formación de la voluntad legislativa. La primera de las razones que abona esta conclusión se relaciona con las especialísimas funciones desplegadas por la Junta en el proceso de conformación de la voluntad legislativa. Como se aprecia de lo establecido en la Ley impugnada, este órgano tiene un impacto fundamental en lo que será la posterior decisión del órgano parlamentario plenario.

El artículo 35 de la LOPCM establece que

[1]a Junta de Coordinación Política representa la pluralidad del Congreso del estado y, por tanto, es el órgano que impulsa el entendimiento y la convergencia política entre todos los diputados y con las instancias y órganos que resulten necesarios, a fin de alcanzar acuerdos para que el Pleno esté en condiciones de adoptar las decisiones que constitucional y legalmente les corresponden. 
La fracción I del artículo 40, por su parte, dispone que la misma debe "impulsar la conformación de acuerdos en torno al contenido de las propuestas, iniciativas o minutas que requieran ser votadas en el Pleno a fin de agilizar el trabajo legislativo" y las diez fracciones restantes le otorgan un abanico de funciones verdaderamente determinantes para el desarrollo de casi todas las tareas propias de la cámara local. ${ }^{15}$ De modo que ni con la ley en la mano ni con el panorama que arroja una mirada somera a la dinámica parlamentaria contemporánea puede afirmarse — como se hace en la resolución-que las tareas de la Junta

no son de carácter esencial ni realizan las facultades legislativas que el Congreso local tiene conferidas en la Constitución Política del Estado de Michoacán de Ocampo, sino que se trata únicamente de funciones que tiene por objeto que la Junta coadyuve en alguna medida con el Pleno, para la mejor realización de sus fines, pero nada más. ${ }^{16}$

La posición de la Junta — es importante subrayarlo - resulta en este sentido muy distinta a la de las comisiones legislativas. Y ello no sólo por este impacto distintivo que, como acabo de señalar, la Junta tiene a la hora de seleccionar los temas que serán discutidos y de preconformar las conclusiones de esta discusión, sino porque la Junta es una y las comisiones son muchas y todo diputado tiene garantizada la pertenencia a por lo menos tres de ellas. ${ }^{17}$ A nivel de discusión comisionada, entonces, la pre-

15 Véanse transcritas en las páginas 97 a 99 de la resolución (formular opiniones sobre los asuntos presentados al Congreso, tratar los asuntos de carácter interno del Congreso, proponer al Congreso la designación o la remoción de una serie de funcionarios estatales de la máxima relevancia, proponer al Pleno los diputados que habrán de integrar la mesa directiva, las comisiones y los comités — previsión que confirma que la Junta tiene un control crucial en la configuración de la dinámica parlamentaria-, etcétera). El artículo 79 de la LOPCM, por su parte, dispone que la Contraloría interna del Congreso, encargada de la revisión y fiscalización de los actos realizados, depende de la Junta de Coordinación Política.

16 Véase la página 96 de la sentencia.

17 Véanse los artículos 47 a 55 de la LOPCM. El artículo 54 de la LOPCM establece que "los diputados pueden pertenecer hasta a tres comisiones. Todo diputado puede participar en cualquier comisión de la que no sea integrante, con voz pero sin voto"; el artículo 52, por su parte, dispone que "las comisiones son colegiadas, integradas pluralmente con un mínimo de tres y un máximo de cinco diputados, presididas por el primero de los nombrados a propuesta de la Junta de Coordinación Política y aprobados por el Pleno; ninguno puede presidir más de una comisión". 
sencia de las minorías parlamentarias en el quehacer de la cámara queda globalmente garantizada sin necesidad de convertir las comisiones en un espejo del Pleno.

La segunda de las razones que abona la posición que suscribo es la constatación de que en un Congreso local como el de Michoacán, los diputados únicos de partido pueden representar una parte muy sustancial del electorado cuyos votos tienen el mismo valor que los que permitieron a los diputados de grupo parlamentario obtener su curul. El impacto exclusorio de no contar con los diputados únicos de partido en la Junta de Coordinación en un Parlamento con 40 miembros es muy alto. Cuando el resultado electoral lleva a que existan dos o incluso tres diputados únicos de partido, la ruptura del equilibrio en el reparto del derecho a participar en la Junta no hace sino agravarse y desembocar en un panorama en cuyo contexto es dudoso que la Junta siga siendo un órgano que "representa la pluralidad del Congreso del estado y por tanto, es el órgano que impulsa el entendimiento y la convergencia política entre todos los diputados" (artículo 35 LOPCM).

Por otro lado, no advierto ningún riesgo de que la integración de los diputados únicos de partido en la Junta no desemboque en un problema opuesto - la sobrerrepresentación de las minorías - porque en el seno de la misma las decisiones finales se toman mediante votación pondera$d a$, de modo que el peso de cada diputado se corresponde con el tamaño de su fuerza representativa. Como algunos colegas y yo mismo hemos destacado en nuestras intervenciones, no parece haber inequidad en un cuerpo que debate con la participación de todos y luego vota de conformidad con un sistema en cuyo contexto el peso del pronunciamiento de cada cual es muy distinto (por ejemplo, el del diputado cuyo grupo parlamentario tenga 16 miembros pesará un $40 \%$ en la decisión final mientras que el de un diputado único sólo pesará un $2.5 \%$ ) y en cambio la diferencia entre participar de algún modo o quedar completamente excluido es muy intensa.

Tampoco hay motivos, en mi opinión, para temer que la inclusión de los diputados únicos obstaculice el funcionamiento interno fluido de este órgano. Los sistemas electorales vigentes en los estados de la República hacen muy improbable un escenario de extrema atomización representativa que desemboque en Juntas de membresía inmanejable y, dado que estamos hablando de diputados únicos y no de diputados independientes 
(cuya presencia o cuya constitución en grupo parlamentario no está prevista por lo demás en la LOPCM) ${ }^{18}$ hay poco peligro de que el sistema sea manipulado por ciertos diputados para forzar su ingreso en la Junta y así multiplicar su poder decisorio al margen del veredicto de las urnas.

\section{CONCLUSIÓN}

Con los razonamientos anteriores he querido explicar y enfatizar que defender la inclusión de los diputados únicos de partido en la Junta de Coordinación Política de un Congreso local nada tiene que ver con la pretensión - al estilo "pendiente resbaladiza"- de que todos los legisladores participen individualmente en todas las tareas y etapas del proceso legislativo, ni amenaza con bloquear el sentido y las condiciones de buen funcionamiento de un órgano como la Junta, ni equivale a abrir las puertas para que las minorías veten o controlen el transcurrir de sus tareas. Por la singular condición de los diputados únicos de partido y por la especialísima posición de la Junta en la conformación de la voluntad parlamentaria, es constitucionalmente problemático que los diputados únicos no puedan siquiera escuchar y ser oídos de algún modo en su seno. Por ello he votado contra la constitucionalidad de una reforma que en mi opinión no abona las condiciones para la equidad de las estructuras representativas y entorpece la expresión de la pluralidad política en el país.

18 La LOPCM no prevé expresamente que los disputados puedan salirse de su grupo parlamentario y continuar ejerciendo sus funciones en condición de diputados independientes. En cualquier caso, en la mayoría de normativas parlamentarias se prevé la agrupación de los independientes en un "grupo mixto" cuya representación en la Junta sólo aumentaría su membresía en una unidad. 